\title{
Development and validation of a new method for the registration of overuse injuries in sports injury epidemiology: the Oslo Sports Trauma Research Centre (OSTRC) Overuse Injury Questionnaire
}

\author{
Benjamin Clarsen, Grethe Myklebust, Roald Bahr
}

- An additional data is published online only. To view this file please visit the journal online (http://dx.doi.org/ 10.1136/bjsports-2012091524)

Oslo Sports Trauma Research Center, Norwegian School of Sport Sciences, Oslo, Norway

\section{Correspondence to}

Benjamin Clarsen, Oslo Sports Trauma Research Center, Norwegian School of Sport Sciences, PO Box 4014 Ullevål Stadion, Oslo 0806, Norway; ben.clarsen@nih.no

Received 28 June 2012 Accepted 3 September 2012 Published Online First 4 October 2012

\footnotetext{
To cite: Clarsen $B$, Myklebust G, Bahr R. Br J Sports Med 2013:47:495502.
}

\begin{abstract}
Background Current methods for injury registration in sports injury epidemiology studies may substantially underestimate the true burden of overuse injuries due to a reliance on time-loss injury definitions.

Objective To develop and validate a new method for the registration of overuse injuries in sports.

Methods A new method, including a new overuse injury questionnaire, was developed and validated in a 13-week prospective study of injuries among 313 athletes from five different sports, cross-country skiing, floorball, handball, road cycling and volleyball. All athletes completed a questionnaire by email each week to register problems in the knee, lower back and shoulder. Standard injury registration methods were also used to record all time-loss injuries that occurred during the study period.

Results The new method recorded 419 overuse problems in the knee, lower back and shoulder during the 3-month-study period. Of these, 142 were classified as substantial overuse problems, defined as those leading to moderate or severe reductions in sports performance or participation, or time loss. Each week, an average of $39 \%$ of athletes reported having overuse problems and $13 \%$ reported having substantial problems. In contrast, standard methods of injury registration registered only 40 overuse injuries located in the same anatomical areas, the majority of which were of minimal or mild severity.

Conclusion Standard injury surveillance methods only capture a small percentage of the overuse problems affecting the athletes, largely because few problems led to time loss from training or competition. The new method captured a more complete and nuanced picture of the burden of overuse injuries in this cohort.
\end{abstract}

\section{INTRODUCTION}

Overuse injuries, defined as those without a specific, identifiable event responsible for their occurrence, may be a substantial problem in many sports. They are thought to be the predominant injury type in sports that involve long, monotonous training sessions, for example, cycling, swimming and long-distance running, ${ }^{1-4}$ as well as in technical sports that involve the repetition of similar movement patterns such as throwing and jumping. ${ }^{5-7}$ They may also be common in team sports such as football, handball and volleyball, particularly at an elite level and among young athletes when the total load on the athlete from training and competition increases rapidly. ${ }^{8-10}$ However, when compared to acute, traumatic injuries such as anterior cruciate ligament ruptures and lateral ankle-ligament sprains, overuse injuries have received very little attention in the sports injury prevention literature. ${ }^{11}$ Valid and reliable data on their magnitude and severity are scarce in almost all sports, and there are very few studies specifically aiming to prevent overuse injuries in sport. ${ }^{12}$

One possible explanation for the lack of knowledge on overuse injuries is that their typical presentation and characteristics make them difficult to record in epidemiological studies, when currently accepted methods of injury registration are used. ${ }^{13}$ Symptoms such as pain or functional limitation most often appear gradually and may be transient in nature, and therefore it is likely that athletes will continue to train and compete despite the presence of overuse conditions, at least in the early phase. In the face of a worsening problem, athletes may try to adapt their training, for example, by refraining from the most aggravating activities or choosing an alternative form of exercise, and at some stage it is also likely that medical treatment will be sought for the injury. It is typically only after these attempts at injury management have failed that athletes will cease participation in training and competition. Furthermore, athletes may choose to defer time loss if possible, for example, by postponing rest or treatment until off-season periods which are not always covered in injury surveillance studies. Thus, it is likely that few overuse injuries lead to time loss from sport. In fact, cross-sectional surveys of athletes from a variety of different sports suggest that it is very common for athletes to continue to train and compete despite the presence of pain and reduced function from overuse injury. ${ }^{1} 8$ 13-15

A vast majority of recently published injury surveillance, risk factor and prevention studies employ registration methods that are based on a consensus statement for the study of injuries in football, published in 2006 and later adapted for other sports. ${ }^{16-19}$ Under these methods, injuries are registered prospectively by researchers or team medical personnel over the course of a study, using one of several possible injury definitions; all physical complaints regardless of their consequences (any physical complaint definition), injuries leading to the athlete seeking attention from a qualified medical practitioner (medical attention definition), or injuries leading to the athlete being unable to fully participate in normal training and competition (time-loss definition). Of these injury definitions, it 
would seem that the first two would be most appropriate for recording overuse conditions, as a 'time-loss' definition would only capture the very worst problems, or the so-called tip of the iceberg. However, apart from special cases such as during shortduration tournaments, ${ }^{3}$ 20-23 the 'any physical complaint' and 'medical attention' definitions are rarely used in injury studies. ${ }^{13}$ Furthermore, irrespective of the injury definition chosen, time loss remains a fundamental component of 'standard' registration methods as it forms the basis for the measurement of injury severity.

We have recently made recommendations for new methodology for measuring the occurrence and severity of overuse injuries in sport. ${ }^{13}$ We suggested that a questionnaire on overuse injuries should be administered to the entire cohort at regular occasions throughout the course of a study. The major benefits with this design would be that the degree of overuse symptoms could be determined for each athlete and monitored over time, and that injury severity measures could be based on changes in an athlete's function or sports performance limitation, rather than on the duration of time loss.

The primary objectives of this study were to develop such a method and to examine the extent to which it may provide greater information on overuse injuries in comparison to standard methods of injury registration. The first step in this process was to develop a new questionnaire suitable to measure the consequences of overuse injuries in sport. The questionnaire was then administered to a group of junior and senior elite Norwegian athletes from a variety of team and individual sports each week for a period of 3 months. During this time, injury registration was also conducted using standard methods as per current recommendations. ${ }^{161719}$

\section{METHODS}

\section{Development of an overuse injury questionnaire}

Question generation and reduction

A new overuse injury questionnaire was developed during a series of group meetings at our institution, attended by sports physiotherapists, medical practitioners, sports injury epidemiologists, athletes and experts in questionnaire design. The intention was to create a questionnaire that could be applied to any overuse injury problem in any area of the body; however, for the purposes of this study, we chose to focus on three common areas of overuse injury among athletes, the knee, lower back and shoulder.

During the initial meetings, a draft list of questions was prepared that included items on injury symptoms, the consequences of overuse injuries on sports participation and performance, and the degree to which injury affected physical functions such as jumping, lifting and throwing.

Interviews were then conducted with athletes and team clinicians from a variety of sports to determine what they considered to be important consequences of overuse injuries, and to provide feedback on the appropriateness and understandability of the draft questions. There was general agreement that pain, limited participation in training and competition, and reduced sporting performance were all important consequences of overuse injury, with several athletes indicating that, of these, limited sports participation was the most important injury consequence. However, several instances arose where athletes felt that the area-specific questions on physical function were irrelevant. For example, cross-country skiers felt that questions relating to jumping and throwing ability were not good measures of injury consequences for their sport.
We therefore chose to eliminate all questions that were areaspecific and related to particular functional activities, and to concentrate on recording pain levels and the consequences of injury on sports participation and sporting performance. After a second round of athlete interviews, four questions were agreed upon that serve as the basis for the assessment of any anatomical area. Figure 1 shows these questions applied to the knee. In studies with multiple anatomical area of interest, the 4 questions are repeated for each area, such that a study of two areas would consist of 8 questions and a study of three areas would consist of 12 questions. In formulating these questions, we chose to use the term 'problem' rather than 'injury', because we felt that

\section{Part 1: Knee Problems}

Please answer all questions regardless of whether or not you have problems with your knees. Select the alternative that is most appropriate for you, and in the case that you are unsure, try to give an answer as best you can anyway.

The term "knee problems" refers to pain, ache, stiffness, swelling, instability/giving way, locking or other complaints related to one or both knees.

\section{Question 1}

Have you had any difficulties participating in normal training and competition due to knee problems during the past week?

Full participation without knee problems

Full participation, but with knee problems

Reduced participation due to knee problems

Cannot participate due to knee problems

\section{Question 2}

To what extent have you reduced you training volume due to knee problems during the past week?

No reduction

To a minor extent

To a moderate extent

To a major extent

Cannot participate at all

\section{Question 3}

To what extent have knee problems affected your performance during the past week?

$\square$ No effect
$\square$ To a minor extent
$\square$ To a moderate extent
$\square$ To a major extent
$\square$ Cannot participate at all
Question 4
To what extent have you experienced knee pain related to your
sport during the past week?
$\square$ No pain
$\square$ Mild pain
$\square$ Moderate pain
$\square$ Severe pain

Figure 1 OSTRC Overuse Injury Questionnaire for knee problems. 
there was a much greater variation in athletes' interpretation of the term 'injury.' Before each anatomical area, the term problem was defined, for example 'pain, aching, stiffness, looseness or other complaints in one or both of your shoulders' and 'pain, aching, stiffness or other problems in your lower back'. We also decided not to ask athletes to attempt to differentiate between acute and overuse problems themselves, as some overuse injuries can have a rapid onset of symptoms and be experienced by an athlete as an acute injury. ${ }^{13}$ Instead, we used the questionnaire to gather information on all types of problems and then manually separated acute injury problems from overuse injuries in the dataset post hoc based on an interview by a sports physiotherapist.

\section{Severity score}

The responses to each of the four questions shown above are allocated a numerical value from 0 to 25 , and these are summed in order to calculate a severity score from 0 to 100 for each overuse problem. The response values were allocated such that 0 represents no problems and 25 represents the maximum level for each question. The values for intermediate responses were chosen in order to maintain as even a distribution from 0 to 25 as possible while still using whole numbers. Therefore, questions 1 and 4 are scored $0-8-17-25$, and questions 2 and 3 are scored $0-6-13-19-25$. The severity score can be used as an objective measure of the consequences of an overuse problem, and can also be plotted for each athlete and used to monitor the progress of overuse problems during the course of a study (see example of typical data in figure 2).

\section{Analysis of psychometric properties of the questionnaire}

A total of 1074 complete questionnaire responses from elite Norwegian athletes were analysed using SPSS statistics software (SPSS V.18, IBM Corporation, New York, USA) to determine the internal consistency of the questionnaire (Cronbach's $\alpha$ ). A factor analysis was also performed using a principle component analysis extraction method. The component matrix was assessed in order to determine whether it would be necessary to weight the questions' contribution to the injury severity score. If the factor loading of each question varied by less than $10 \%$, this was taken as a sign that weighting the responses would be of little value. ${ }^{24}$

\section{Determination of the face validity of the new method}

In order to establish the face validity of the new method's ability to identify and measure overuse problems at the knee, lower back and shoulder, it was applied in a 3-month study of 313 elite Norwegian junior and senior athletes from a variety of sports, including cross-country skiing, floorball, handball, road cycling and volleyball (table 1). During this period, the new questionnaire was administered to all subjects on a weekly basis. At the same time, a parallel registration of time-loss injuries was also conducted using standard methods of injury registration.

\section{Inclusion}

We approached team coaches and asked whether they were interested in participation in the study, and if they expressed interest, all athletes in the team were provided with information about the study and asked to consent to participation. The study was approved by the Norwegian Data Inspectorate and reviewed by the South-Eastern Norway Regional Committee for Research Ethics.
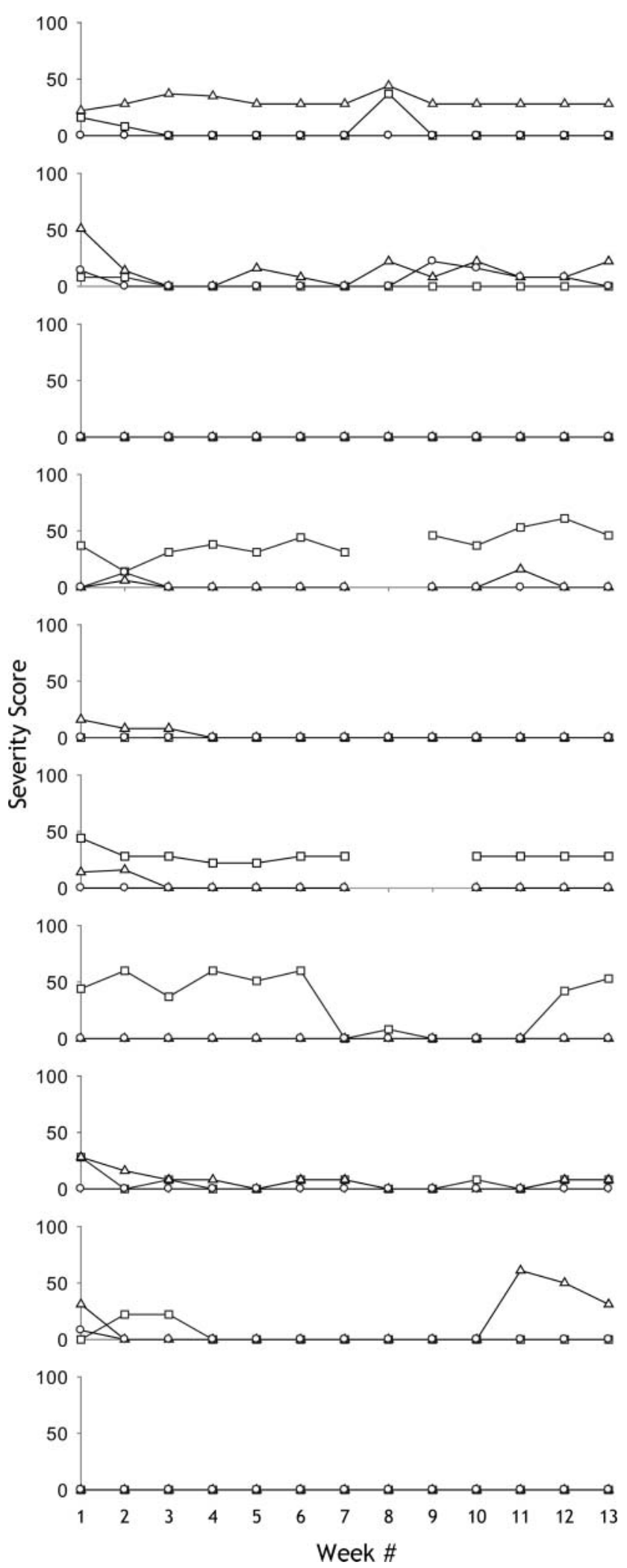

Figure 2 Examples of the severity score being used to track the consequences of overuse problems over the course of a 13-week study in 10 randomly selected athletes. Squares: knee severity score, triangles: lower back severity score, circles: shoulder severity score. Note that two athletes have missing data.

\section{Injury registration: new method}

Each athlete was asked to provide their email address when giving their written consent to participation in the study. Online 
Table 1 Characteristics of the participants $(n=313)$

\begin{tabular}{lrrrrr}
\hline & $\begin{array}{l}\text { Cycling } \\
(\mathbf{n}=98)\end{array}$ & $\begin{array}{l}\text { Floorball } \\
(\mathbf{n}=50)\end{array}$ & $\begin{array}{l}\text { Handball } \\
(\mathbf{n}=55)\end{array}$ & $\begin{array}{l}\text { Volleyball } \\
(\mathbf{n}=65)\end{array}$ & $\begin{array}{l}\text { XC skiing } \\
(\mathbf{n}=\mathbf{4 5})\end{array}$ \\
\hline Female/male (n) & \multicolumn{1}{c}{$14 / 84$} & \multicolumn{1}{c}{$17 / 33$} & $36 / 19$ & $38 / 27$ & $16 / 29$ \\
Age (year) & $21(4)$ & $22(5)$ & $20(4)$ & $18(1)$ & $18(1)$ \\
Height $(\mathrm{cm})^{*}$ & $181(7)$ & $176(8)$ & $177(10)$ & $179(11)$ & $177(8)$ \\
${\text { Weight }(\mathrm{kg})^{*}}^{*}$ & $70(7)$ & $70(9)$ & $73(13)$ & $70(10)$ & $67(8)$ \\
Years participating & $6(4)$ & $9(4)$ & $12(4)$ & $6(2)$ & $10(3)$ \\
in the sport (n)* & & & & & \\
\hline
\end{tabular}

*Values are shown as the mean with the standard deviation in parenthesis. $\mathrm{XC}=$ cross-country.

survey software (Questback V. 9692, Questback AS, Oslo, Norway) was then used to send the overuse problem questionnaire to that address every week for 13 weeks. If no response had been received from an athlete after 3 days, they were automatically sent a reminder email, and if an athlete failed to respond for three consecutive weeks, they were contacted by telephone to encourage them to continue to participate in the project.

The questionnaire included the abovementioned four questions on the consequences of overuse problems at the knee, the lower back and the shoulder. These questions were preceded by a short introduction explaining that all questions should be completed, regardless of whether or not the athlete had experienced any problems in that area, and giving examples of the most common overuse symptoms for each area. The survey software prevented questionnaire submission if all items were not fully completed. The complete questionnaire is available as an online supplementary appendix in the online version of this article.

\section{Injury registration: standard method}

In the handball, floorball and volleyball teams, time-loss injuries were registered during scheduled training sessions by the team coach or physiotherapist, according to the methods described in the consensus statement for injury surveillance methods in football. ${ }^{16}$ However, as road cyclists and cross-country skiers typically train individually rather than as a team, this was not possible in these groups. We therefore employed methods similar to those described by Nilstad et al, ${ }^{25}$ whereby an extra question was added into their weekly questionnaires that asked whether they had had any form of physical complaint that prevented them from being fully able to train or compete in their sport. Any athletes that answered 'yes' to this question were contacted by a researcher on the telephone, and injuries that satisfied a time-loss injury definition were registered using standard methods. The extra question was added to the end of the questionnaire, after the specific questions on knee, lower back and shoulder problems had been answered. It was stated clearly that they should report any problem, regardless of whether or not they had already reported the same one in the previous questions.

\section{Telephone interviews}

At the conclusion of the study, all athletes were interviewed by a sports physiotherapist to confirm that all injury information we had received via both registration methods was correct. All injuries that were associated with a specific, identifiable event were classified as acute injuries. If an acute injury had been sustained in the knee, shoulder or lower back, data corresponding to these injuries that were obtained through the overuse injury questionnaires were separated in the database.

\section{Data analysis}

Each week the prevalence of overuse problems was calculated for each anatomical area by dividing the number of athletes that reported any type of problem in that area by the number of questionnaire respondents. A similar calculation was made for the number of athletes who reported problems leading to moderate or severe reductions in training volume, or moderate or severe reductions in sports performance or complete inability to participate in sport (ie, athletes who selected option 3, 4 or 5 in either Question 2 or Question 3). This is referred to as the prevalence of substantial overuse problems. The average severity score for each anatomical area was also calculated weekly by averaging the score of all athletes that reported a problem. At the conclusion of the study, the weekly average of these measures were calculated for each anatomical area: the average weekly prevalence of all problems, the average weekly prevalence of substantial problems, the average severity score and the average number of weeks that each problem was reported. A 95\% confidence interval was calculated for each of these measures.

\section{Modelling the effects of different sampling frequencies and removing the first questionnaire}

In order to assess the effects of sampling less frequently, the abovementioned outcome measures were recalculated using only information from every second questionnaire and every fourth questionnaire. Outcome measures were also recalculated after removing the first questionnaire, and a related-samples Wilcoxon paired rank test was used to analyse differences between the first and second weeks in the prevalence of problems reported in each anatomical area in the five different sports.

\section{RESULTS}

\section{Standard method}

Weekly injury reports were completed by coaches of the handball, floorball and volleyball teams for every week of the project, and in the individual sports, all injuries reported at the end of the questionnaire were successfully registered by telephone interview. Using these methods, a total of 103 time-loss injuries, 42 acute and 61 overuse injuries, were recorded among 82 athletes during the course of the study (table 2). Of the 61 overuse injuries, 40 were located in the knee, lower back or shoulder; 18 were new injuries and 22 were recurrent injuries. These 40 injuries were distributed among 33 athletes, equating to $11 \%$ of the cohort. Most knee, lower back and shoulder injuries were of minimal severity (48\%); 15\% were mild, 25\% moderate and $13 \%$ severe.

\section{New method}

The average weekly response rate to the overuse injury questionnaire was $93 \%$, with $81 \%$ of athletes responding to all 13 questionnaires administered during the course of the study. A total of 419 overuse conditions were identified, affecting 236 athletes (75\% of the cohort). Fifty-two per cent of all athletes registered conditions located at the knee, $43 \%$ at the shoulder and $40 \%$ at the lower back. Forty-four per cent of all problems were present at the beginning of the study. Of all overuse conditions, $17 \%$ only involved minor pain and did not have any consequences on sporting participation or performance, whereas 34\% were classified as substantial problems. Thirty-six percent of the 
Table 2 Location and severity of time-loss injuries identified by standard injury surveillance methods

\begin{tabular}{|c|c|c|c|c|c|}
\hline & $\begin{array}{l}\text { Minimal } \\
\text { (1-3 days) }\end{array}$ & $\begin{array}{l}\text { Mild } \\
\text { (4-7 days) }\end{array}$ & $\begin{array}{l}\text { Moderate } \\
\text { (8-28 days) }\end{array}$ & $\begin{array}{l}\text { Severe } \\
\text { (>28 days) }\end{array}$ & Total \\
\hline \multicolumn{6}{|l|}{ Acute injuries } \\
\hline Head and face & 3 & 0 & 2 & 0 & 5 \\
\hline Finger & 0 & 1 & 1 & 0 & 2 \\
\hline Ribs & 1 & 0 & 0 & 0 & 1 \\
\hline Lumbar spine & 0 & 0 & 1 & 0 & 1 \\
\hline $\begin{array}{l}\text { Pelvis/sacrum/ } \\
\text { buttock }\end{array}$ & 0 & 1 & 0 & 0 & 1 \\
\hline Thigh & 2 & 0 & 1 & 0 & 3 \\
\hline Knee & 2 & 1 & 3 & 0 & 6 \\
\hline Lower leg & 1 & 0 & 0 & 0 & 1 \\
\hline Ankle & 6 & 3 & 7 & 2 & 18 \\
\hline Foot/toe & 1 & 1 & 2 & 0 & 4 \\
\hline Total & 16 & 7 & 17 & 2 & 42 \\
\hline \multicolumn{6}{|l|}{ Overuse injuries } \\
\hline Ankle & 2 & 0 & 1 & 0 & 3 \\
\hline Foot/toe & 0 & 0 & 1 & 0 & 1 \\
\hline Hip and groin & 0 & 0 & 1 & 0 & 1 \\
\hline Knee & 12 & 4 & 8 & 4 & 28 \\
\hline Lower leg & 4 & 2 & 1 & 0 & 7 \\
\hline Lumbar spine & 7 & 2 & 1 & 0 & 10 \\
\hline $\begin{array}{l}\text { Pelvis/sacrum/ } \\
\text { buttock }\end{array}$ & 0 & 0 & 0 & 1 & 1 \\
\hline Shoulder & 0 & 0 & 1 & 1 & 2 \\
\hline Wrist & 0 & 0 & 1 & 0 & 1 \\
\hline Thigh & 4 & 1 & 0 & 2 & 7 \\
\hline Total & 29 & 9 & 15 & 8 & 61 \\
\hline
\end{tabular}

cohort experienced a substantial problem at some stage during the course of the study. The average weekly prevalence of all problems and substantial problems, the average weekly severity score and the average duration of problems is shown in table 3. Figure 3 shows the number of cases recorded by the two different methods. Figure 4 illustrates data reported by the 10 athletes with the highest cumulative severity scores over the 3 -month period. Of the 23 overuse conditions reported by these athletes, 7 were also recorded with the standard method.

\section{Effects of different sampling frequencies on outcome measures}

Sampling less frequently led to fewer cases being identified; however, the average prevalence and average severity measures were not affected (table 4). The greatest prevalence of overuse problems in all anatomical areas was reported in the first questionnaire $(p<0.01)$, and reanalysis of the dataset after removing the first questionnaire led to a $14 \%$ reduction in the number of problems being identified without affecting the average prevalence or average severity score.

\section{Psychometric questionnaire properties}

The questionnaire had high internal consistency, with a Chronbach's $\alpha$ of 0.91 . This was not improved any further by removing items (table 5). The factor weighting ranged from 0.86 to 0.91 for the four questions, suggesting that there is a little reason to weight items in the calculation of the severity score.
Table 3 Average weekly prevalence of all overuse problems and of substantial problems, average weekly severity score and average duration of cases

\begin{tabular}{lccc}
\hline & $\begin{array}{l}\text { Knee } \\
(161 \text { cases) }\end{array}$ & $\begin{array}{c}\text { Lower back } \\
(135 \text { cases) }\end{array}$ & $\begin{array}{l}\text { Shoulder } \\
(123 \text { cases) }\end{array}$ \\
\hline $\begin{array}{l}\text { Average weekly prevalence (all } \\
\text { problems) }\end{array}$ & $24(21-27)$ & $16(13-19)$ & $12(10-15)$ \\
$\begin{array}{l}\text { Average weekly prevalence } \\
\text { (substantial problems)* }\end{array}$ & $8(7-8)$ & $3(2-4)$ & $2(2-3)$ \\
$\begin{array}{l}\text { Average weekly severity score } \\
\text { Average duration of cases } \\
\text { (weeks) } \dagger\end{array}$ & $31(30-32)$ & $24(22-25)$ & $24(22-25)$ \\
\hline $\begin{array}{l}\text { *Values are shown as percentages with the 95\% Cl in parentheses. } \\
\text { t95\% Cl in parentheses. } \\
\text { Substantial problem: overuse problem causing moderate/severe reductions in training } \\
\text { volume or sports performance or complete inability to participate in training or } \\
\text { competition. }\end{array}$ & $6(5-6)$ & $4(4-5)$ & $4(3-5)$ \\
\end{tabular}

\section{DISCUSSION}

The ability to validly and reliably record overuse conditions presents a particular problem in sports injury epidemiology, largely due to the fact that athletes often continue to train and compete despite the existence of overuse problems. This study clearly highlights the inadequacy of currently accepted injury registration methods to record the true magnitude of overuse problems, given that the new method identified more than 10 times as many cases than the standard method and demonstrated that $75 \%$, rather than $11 \%$, of athletes were affected during the 3 -month study period. However, objective comparison of the two methods is difficult as we are proposing a completely different paradigm for the recording and reporting of overuse problems. An appraisal of the potential benefits and limitations of the new method must therefore be largely qualitative in nature.

The first factor that prevents direct comparison of the results of each method is that we have not only compared two different ways of collecting injury data but also two different injury definitions. The standard method used a time-loss definition, only recording injuries that lead to a cessation of training or competition for at least 1 day, whereas the new method recorded all physical complaints even if the only symptom was mild pain. A far greater number of problems would therefore be expected to have been captured using the all physical complaints definition, regardless of the registration methods used. Although it would

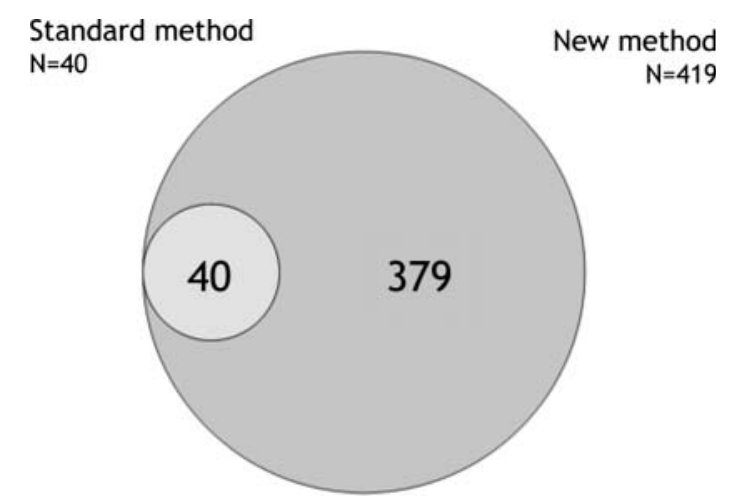

Figure 3 Venn diagram of the number of overuse problems identified by the standard injury registration method and the new method. All injuries registered using the standard method was classified as substantial overuse problems by the new method. 

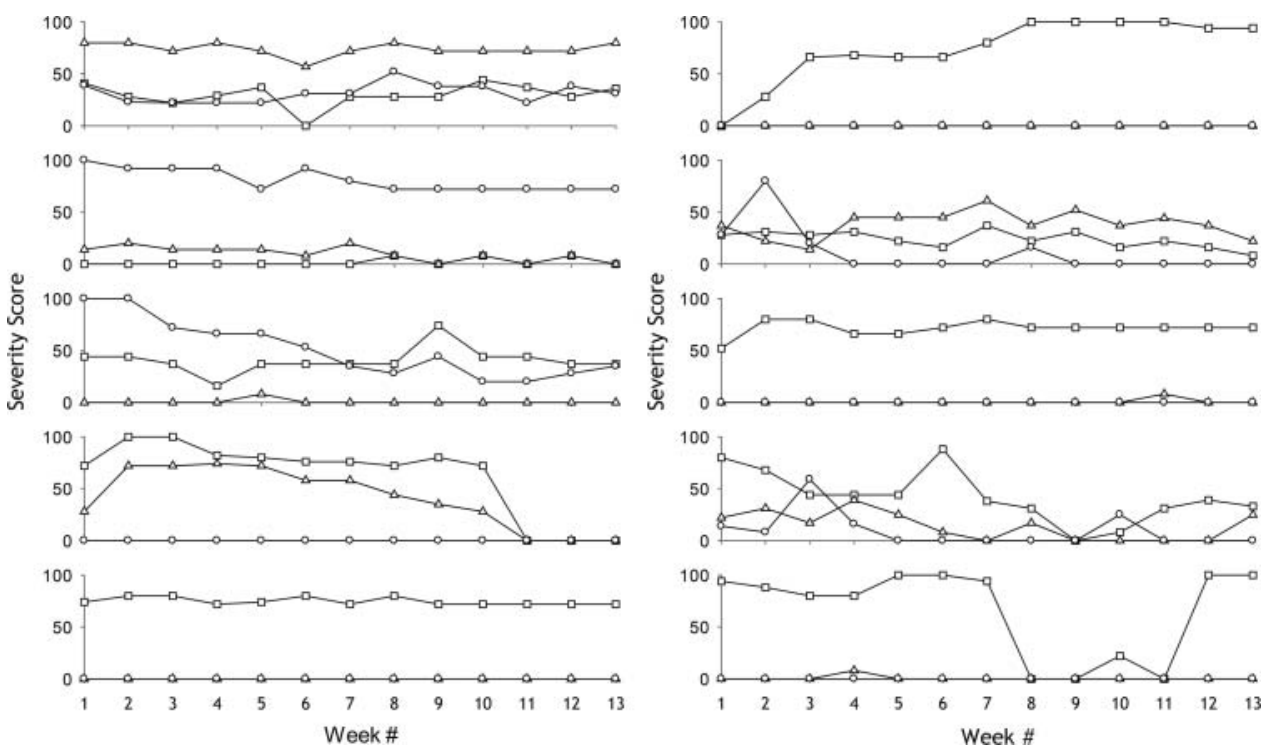

Figure 4 Athletes with the 10 highest cumulative severity scores during the 13-week study. Squares: knee severity score, triangles: lower back severity score, circles: shoulder severity score.

have been possible to have used a similar definition for the standard method, we chose to use a time-loss definition because it is currently the most commonly used definition in the recent sports epidemiology literature. ${ }^{13}$ Broader definitions, such as all physical complaints or medical attention, may be seldom used because they greatly increase the burden on injury recorders and because there are concerns over their reliability of the information they collect. For example, the number of injuries recorded will vary depending on the extent of contact between injury recorders and athletes, and different injury recorders are likely to have differing interpretations of what constitutes a recordable event. ${ }^{26}$ In contrast, the new method may be less susceptible to

Table 4 Variations in outcome measures with different sampling frequencies

\begin{tabular}{lllll}
\hline & Sample & $\begin{array}{l}\text { Sample } \\
\text { weekly } \\
\text { exclude } \\
\text { week } 1\end{array}$ & $\begin{array}{l}\text { Sample } \\
\text { every } \\
\text { 2 weeks* }\end{array}$ & $\begin{array}{l}\text { Sample } \\
\text { every } \\
\text { 4 weekst }\end{array}$ \\
\hline $\begin{array}{l}\text { Number of } \\
\text { completed } \\
\text { questionnaires }\end{array}$ & 3848 & 3538 & 1774 & 896 \\
$\begin{array}{l}\text { Number of } \\
\text { problems }\end{array}$ & 419 & 361 & 318 & 280 \\
$\begin{array}{l}\text { Number of } \\
\text { substantial } \\
\text { problems }\end{array}$ & 142 & 124 & 94 & 72 \\
$\begin{array}{l}\text { Average } \\
\text { prevalence } \\
\text { (all problems) }\end{array}$ & $39(34-44)$ & $37(34-41)$ & $39(34-44)$ & $40(31-50)$ \\
$\begin{array}{l}\text { Average } \\
\text { prevalence } \\
\text { (substantial) }\end{array}$ & $13(12-15)$ & $12(11-14)$ & $13(10-15)$ & $13(9-17)$ \\
$\begin{array}{l}\text { Average severity } \\
\text { score } \\
\text { Average duration } \\
\text { of problems } \\
\text { (weeks) }\end{array}$ & $28(27-29)$ & $28(27-29)$ & $28(26-29)$ & $27(26-27)$ \\
\hline
\end{tabular}

*Weeks $2,4,6,8,10$ and 12

† Weeks 2,6 and 10 . these sources of bias as data are reported directly by athletes rather than third-party injury recorders. While the information collected remains subjective, it reflects the consequences of overuse problems that are relevant for each athlete and this is unlikely to vary systematically between different cohorts. The ability to compare broad-definition injury data between studies is therefore greatly enhanced using the new method.

A second factor that prevents direct comparison of the two methods is that each one expresses the rate and severity of injuries in different ways. Traditionally, injury rates are expressed as an incidence, most often as the number of new injuries per $1000 \mathrm{~h}$ of sports participation. ${ }^{27}$ However, incidence fails to account for injuries that are present at the start of a study, and this may preclude the registration of a large proportion of overuse problems. For example, in the present study, $44 \%$ of cases identified using the new method would have been excluded from incidence calculations for this reason. We therefore chose to express the rate of overuse problems as an average prevalence with a 95\% CI. This effectively reflects the proportion of athletes that could be expected to be affected by overuse problems at any given point during the study. The average prevalence of substantial problems was also reported, as this measure filters out the most minor problems and thereby provides important information on the true burden of overuse injury among a group of athletes.

Table 5 Inter-item and item-total correlations and effects of removing items on internal consistency

\begin{tabular}{|c|c|c|c|c|c|}
\hline & \multicolumn{3}{|c|}{ Inter-item correlation matrix } & \multirow[b]{2}{*}{$\begin{array}{l}\text { Item-total } \\
\text { correlation }\end{array}$} & \multirow{2}{*}{$\begin{array}{l}\text { Cronbach's } \\
\alpha \text { if item } \\
\text { deleted }\end{array}$} \\
\hline & $\begin{array}{l}\text { Question } \\
1\end{array}$ & $\begin{array}{l}\text { Question } \\
2\end{array}$ & $\begin{array}{l}\text { Question } \\
3\end{array}$ & & \\
\hline Question 1 & - & & & 0.80 & 0.88 \\
\hline Question 2 & 0.70 & - & & 0.74 & 0.90 \\
\hline Question 3 & 0.75 & 0.72 & - & 0.85 & 0.85 \\
\hline Question 4 & 0.73 & 0.64 & 0.80 & 0.82 & 0.87 \\
\hline
\end{tabular}


Injury severity is also expressed in different ways by the two methods. Traditionally, it is expressed as the number of days taken from the time of injury until the athlete resumes full training and competition, and if the injury does not lead to time loss, it is recorded as being of ' 0 days' severity. In the current study, this situation applied to a majority of overuse problems, despite the fact that many of these so-called 'slight' problems led to reduced performance, pain and modified participation that lasted for many weeks. Clearly, basing severity on time loss alone underestimates the true impact of overuse problems. Furthermore, even when an overuse problem does cause time loss, it is often interspersed between repeated attempts to return to training and competition. ${ }^{13}$ Although suggestions have been made on how to deal with such problems, ${ }^{28}$ most studies using standard methods adopt return-to-play criteria for defining injury resolution, meaning that fluctuating problems are treated as separate events, each time the athlete returns to full training and competition. This is obviously an invalid representation of the true nature of such injuries.

The new method therefore measures the severity of overuse problems using the severity score, which reflects the athlete's selfassessment of their pain and the impact that the problem has had on their participation, training volume and sports performance. Due to the subjectivity of this method, the validity of directly comparing individual athlete's questionnaire responses is questionable; however, the severity score is useful in monitoring the progression of overuse problems over time, such as in the examples displayed in figures 2 and 3. This approach may be of particular benefit if the new method is used as a practical injury surveillance tool. Furthermore, as there is little reason to suspect a systematic bias in severity scores between different groups of athletes, the average severity score can be used as the basis for comparison between groups. Future studies may also calculate the area under each athlete's injury curve such as those shown in figures 2 and 4, and use that number as a reflection of the total burden of each overuse problem. In this way, a long duration problem of mild or moderate severity may be scored higher than a more severe one that is only of a brief duration. This technique may be particularly relevant when applying the new method in risk factor and prevention studies; however, missing data will be a complicating factor when making these calculations.

A final advantage of the new method is that it is likely to be a cheaper alternative than traditional methods of data collection as once the survey software has been set up, all questionnaires and reminders are automatically delivered each week for the duration of the study. This is likely to be far less costly than paying research staff to manually record injuries.

The new method does, however, have several limitations. First, as information is based on athlete self-reports and the definition of a recordable problem is very broad, it is possible that some of the cases recorded may in fact be 'normal' pain related to athletic participation rather than an overuse injury, for example, delayed-onset muscle soreness. This may be particularly relevant for the $17 \%$ of cases that only involved minor pain and had no consequences on sports performance or participation. Ideally, the solution to this problem is that each problem reported by an athlete is quickly followed up with a confirmatory medical examination; however, this obviously increases the logistical difficulty and cost of conducting a study.

A second limitation of the method is that the validity of the recorded information is dependent on a high response rate throughout the course of the study. As the burden of injury registration is placed upon athletes, much attention and effort needs to be paid to motivating them to respond to each questionnaire. In the current study, the average response rate of $93 \%$ was very high; however, it is unknown whether such a good rate could have been maintained over a longer period of time. Future studies that involve a longer duration of data collection may need to be performed with less frequent questionnaire administration, for example, every second week or every month. This may also be the case for studies of recreational or non-elite athletes who may be less motivated to report injury data so frequently. In order to assess the effect of this, we performed data simulations with information from every second and every fourth questionnaire. The results indicate that when sampling less frequently, the average prevalence and severity score measures remain unchanged, while the number of problems identified is reduced. Based on these findings, sampling less frequently may be acceptable; however, if this is done, it is important to recognise that some shorter duration problems will be missed. We recommend that regardless of the sampling frequency, the retrospective period of registration of problems should not extend beyond 7 days, in order to minimise the risk of recall bias.

In our data simulation, we also analysed the effect of removing the results of the first questionnaire from the dataset. This led to a slight reduction in the number of reported cases, but did not affect the average prevalence measures or the severity score. We performed this analysis because the first questionnaire identified the highest prevalence of overuse problems in every anatomical area in every group of athletes, and this could not be explained by seasonal variation as the data were not collected at exactly the same time, and each group of athletes were in different periods of their season during the collection period. We therefore suspect that the first questionnaire returns an artificially high rate of overuse problems, and suggest that with future use of the new method these data should be excluded from the final dataset.

The new method is also dependent on the athletes providing honest information, which may be a concern if they feel that reporting an overuse problem may have adverse effects for them, such as on their chances of team selection. In order to minimise this risk, we were careful to explicitly guarantee confidentiality in the information letter prior to the study and in the introduction to the questionnaire they received each week. However, as with all forms of injury surveillance, it is hard to verify the extent to which athletes report the truth and this remains a threat to the validity of the data.

Another limitation to the new method is that the amount of details that can be collected directly from athletes is limited. The questionnaire only collects information on the anatomical location of each problem, rather than the injury type or specific diagnosis. This is because we do not expect that athletes will be able to reliably report this information, which should ideally be based on a clinical examination. Similarly, in the current study, we used telephone interviews to differentiate between acute and overuse injuries because we were concerned that so-called sudden-onset overuse injuries may have been misclassified if athletes had been asked to differentiate between the two types themselves. However, this approach is not without problems as it limits the potential sample size of a study and retrospective telephone interviews are subject to interviewer and recall bias. Alternative means of differentiating between acute injuries and overuse problems may be necessary in future studies.

A final limitation of the new method is that in its current form it only collects data on predefined injury areas. The method therefore needs to be modified in order to be used in studies where the research objective is a general registration of all types of overuse problems. However, when the objective is to study specific overuse problems, the current approach may be preferable as previous studies have shown that general 
questioning on overuse injuries leads to fewer problems being identified than when specific questions on predefined areas are used. ${ }^{1}$

\section{CONCLUSION}

We have developed a new method for the registration of overuse problems in sports injury epidemiology. As demonstrated by this study, the new approach offers several advantages over standard methods, particularly as it allows for the use of a

\section{What are the new findings?}

- Standard methods of injury registration using a time-loss injury definition may be insufficient for the study of overuse injuries.

- When studying overuse injuries, all physical complaints need to be recorded and severity measures need to be based on pain and the consequences of injury on athletes' participation and sporting performance.

- The rate of overuse problems should be expressed using prevalence and severity measures, rather than incidence.

\section{How might it impact on clinical practice in the near} future?

- This paper may lead to a change in the methods that are used to register the magnitude and severity of overuse problems in epidemiological studies of sports injuries.

broad injury definition and a means of quantifying injury severity that is not dependent on time loss. The new method may therefore be a better alternative for the specific study of overuse problems in sport.

Acknowledgements The authors acknowledge M Engedal, G Midtsundstad, L Rosenlund and $\mathrm{G}$ Thorsen for their contribution in developing the new method and collecting data. We also thank MA Risberg, EM Roos and I Holme for their assistance in the development of the questionnaire. The Oslo Sports Trauma Research Center has been established at the Norwegian School of Sport Sciences through generous grants from the Royal Norwegian Ministry of Culture, the South-Eastern Norway Regional Health Authority, the International Olympic Committee, the Norwegian Olympic Committee \& Confederation of Sport, and Norsk Tipping AS

Correction notice This article has been corrected since it was published Online First. The section ': the Oslo Sports Trauma Research Centre (OSTRC) Overuse Injury Questionnaire' has been added to the title. The text reference to figure 1 has also been corrected.

Contributors All authors were involved in planning the project, the development of the questionnaire and in writing the manuscript. $\mathrm{BC}$ was also responsible for coordination of the data collection and for data analysis. $B C$ is responsible for the overall content as guarantor.

Competing interests None.

Ethics approval South-Eastern Norway Regional Committee for Research Ethics.

Provenance and peer review Not commissioned; externally peer reviewed.

Data sharing statement All unpublished data are available upon request. However, we are planning a second article based on the same data set describing the prevalence and severity of overuse injuries in each of the five sports. This paper will shed additional light on the validity of the new method.

\section{REFERENCES}

1 Clarsen B, Krosshaug T, Bahr R. Overuse injuries in professional road cyclists. Am J Sports Med 2010;38:2494-501.

2 Knobloch K, Yoon U, Vogt PM. Acute and overuse injuries correlated to hours of training in master running athletes. Foot Ankle Int 2008;29:671-6.

3 Mountjoy M, Junge A, Alonso JM, et al. Sports injuries and illnesses in the 2009 FINA World Championships (Aquatics). Br J Sports Med 2010;44:522-7.

4 Ristolainen $L$, Heinonen $A$, Turunen $H$, et al. Type of sport is related to injury profile: a study on cross country skiers, swimmers, long-distance runners and soccer players. A retrospective 12-month study. Scand J Med Sci Sports 2010;20:384-93.

5 Lian OB, Engebretsen L, Bahr R. Prevalence of jumper's knee among elite athletes from different sports: a cross-sectional study. Am J Sports Med 2005:33:561-7.

6 Jacobsson J, Timpka T, Kowalski J, et al. Prevalence of musculoskeletal injuries in Swedish elite track and field athletes. Am J Sports Med 2011:40:163-9.

7 Fleisig GS, Andrews JR, Cutter GR, et al. Risk of serious injury for young baseball pitchers: a 10-year prospective study. Am J Sports Med 2011;39:253-7.

8 Myklebust G, Hasslan L, Bahr R, et al. High prevalence of shoulder pain among elite Norwegian female handball players. Scand J Med Sci Sports. Published Online First 11 November 2011. doi:10.1111/j.1600-0838.2011.01398.x.

9 Dupont G, Nedelec M, McCall A, et al. Effect of 2 soccer matches in a week on physical performance and injury rate. Am J Sports Med 2010;38:1752-8.

10 Visnes $H$, Bahr R. Training volume and body composition as risk factors for developing jumper's knee among young elite volleyball players. Scand J Med Sci Sports. Published Online First 20 January 2012. doi:10.1111/ j.1600-0838.2011.01430.x

11 Cook J, Finch C. The long-term impact of overuse injuries on life-long participation in sport and health status. In: Farelli AD. Sport participation. Hauppauge, NY: Nova Science Publisher's, 2011:85-104

12 van Wilgen $C P$, Verhagen $E A$. A qualitative study on overuse injuries: the beliefs of athletes and coaches. J Sci Med Sport 2012;15:116-21.

13 Bahr R. No injuries, but plenty of pain? On the methodology for recording overuse symptoms in sports. Br J Sports Med 2009:43:966-72.

14 Harringe $M L$, Lindblad $S$, Werner $S$. Do team gymnasts compete in spite of symptoms from an injury? Br J Sports Med 2004;38:398-401.

15 Vleck VE, Bentley DJ, Millet GP, et al. Triathlon event distance specialization: training and injury effects. J Strength Cond Res 2010;24:30-6.

16 Fuller CW, Ekstrand J, Junge A, et al. Consensus statement on injury definitions and data collection procedures in studies of football (soccer) injuries. Br J Sports Med 2006;40:193-201.

17 Fuller CW, Molloy MG, Bagate C, et al. Consensus statement on injury definitions and data collection procedures for studies of injuries in rugby union. Clin J Sport Med 2007;17:177-81.

18 Junge $\mathrm{A}$, Engebretsen $\mathrm{L}$, Alonso JM, et al. Injury surveillance in multi-sport events: the International Olympic Committee approach. Br J Sports Med 2008:42:413-21.

19 Pluim BM, Fuller CW, Batt ME, et al. Consensus statement on epidemiological studies of medical conditions in tennis, April 2009. Clin J Sport Med 2009:19:445-50

20 Alonso JM, Junge A, Renstrom P, et al. Sports injuries surveillance during the 2007 IAAF World Athletics Championships. Clin J Sport Med 2009;19:26-32.

21 Alonso JM, Tscholl PM, Engebretsen L, et al. Occurrence of injuries and illnesses during the 2009 IAAF World Athletics Championships. Br J Sports Med 2010:44:1100-5.

22 Engebretsen L, Steffen $\mathrm{K}$, Alonso JM, et al. Sports injuries and illnesses during the Winter Olympic Games 2010. Br J Sports Med 2010;44:772-80.

23 Junge A, Engebretsen L, Mountjoy ML, et al. Sports injuries during the Summer Olympic Games 2008. Am J Sports Med 2009:37:2165-72.

24 Streiner DL, Norman GR. Health Measurement Scales. Oxford: Oxford University Press, 2008:136-7.

25 Nilstad A, Bahr R, Andersen T. Text messaging as a new method for injury registration in sports: a methodological study in elite female football. Scand J Med Sci Sports. Published Online First 27 April 2012. doi:10.1111/ j.1600-0838.2012.01471.x

26 Orchard J, Hoskins W. For debate: consensus injury definitions in team sports should focus on missed playing time. Clin J Sport Med 2007;17:192-6.

27 van Mechelen W, Hlobil H, Kemper HC. Incidence, severity, aetiology and prevention of sports injuries. A review of concepts. Sports Med 1992;14:82-99.

28 Fuller CW, Bahr R, Dick RW, et al. A framework for recording recurrences, reinjuries, and exacerbations in injury surveillance. Clin J Sport Med 2007;17:197-200. 